\title{
Original
}

Journal of Hard Tissue Biology 24[2] (2015) 123 -133

\section{In Vitro Culture of BMSCs on VEGF-SF-CS Three-Dimensional Scaffolds for Bone Tissue Engineering}

\author{
Shuang Tong, Lei Xue, Da-peng XU, Zi-mei Liu and Xu-kai Wang
}

Department of Oral and Maxillofacial Surgery, School of Stomatology, China Medical University, Liaoning Institute of Dental Research, Shenyang110002, Liaoning province, China

(Accepted for publication, January 30, 2015)

\begin{abstract}
The objective of the study was to discuss the biocompatibility of VEGF-silk fibroin-chitosan (VEGFSF-CS) three-dimensional scaffolds in order to offer an ideal scaffold for bone tissue engineering. Bone marrow derived mesenchymal stem cells (BMSCs) were seeded on the VEGF-SF-CS three-dimensional scaffolds and silk fibroin-chitosan (SF-CS) three-dimensional scaffolds. On VEGF-SF-CS and SF-CS three-dimensional scaffolds, the cell adhesion rate was increased as time went on. Scanning electron microscopy: The cells grew actively and had normal multiple fissions, granular and filamentous substrates could be seen around the cells, and cell microfilaments were closely connected with the scaffolds. The cells could not only show attached growth on surfaces of the scaffolds, but could also extend into the scaffolds. CCK-8 and ALP analysis proved that the vascular endothelial growth factor (VEGF) could significantly promote BMSCs growth and proliferation in the SF-CS scaffolds; however, the enhancement of BMSCs cell proliferation and activity by VEGF is dependent on time. Thus, VEGF-SF-CS composite scaffolds represent a promising new type of scaffold for bone tissue engineering.
\end{abstract}

Key words: Silk fibroin, Chitosan, Bone tissue engineering, Bone marrow derived mesenchymal stem cells, Vascular endothelial growth factor

\section{Introduction}

Repair of bone defects resulting from trauma, congenital malformations, and surgical resections remains a challenge that is being addressed by advanced bone tissue engineering approaches ${ }^{1,2)}$. A combinatorial approach for treating large bone defects include seeding cells, growth factors and biomaterials used in bone tissue engineering, can further enhance the success of cell therapy in this scenario ${ }^{3-7)}$.

BMSCs derived from bone marrow are an obvious source of autologous stem cells, and used as seeding cells for cell therapy and tissue engineering ${ }^{8-11)}$. A number of studies have demonstrated that autologous BMSCs cultured in scaffolds can induce new bone formation in vivo and lead to improved healing of critical-size defects $^{12-15)}$. In some studies, BMSCs were induced into osteoblastlike cells with the osteogenic medium before transplantation. Osteoblast-like cells derived from BMSCs shared similar characters with osteoblasts. Osteoblast-like cells had a good ability of growth and proliferation and keeped their biological characteristics constant after several passages. In addition,

Correspondence to: Dr. Xu-kai Wang, Department of Oral and Maxillofacial Surgery, School of Stomatology, China Medical University, No.117, Nan Jing North Street, HePing District, Shenyang 110002, Liaoning Province, PR China; Tel: +8602422892451; E-mail: wangxukai757892@sina.com osteoblas-like cells could secrete much bone matrix to form mature bone with deposition of calcium salts, and played an important role in osteogenesis and bone regeneration ${ }^{16)}$. BMSCs can differentiate in bone, chondrogenic and osteogenic lineages upon specific induction with appropriate chemicals and factors ${ }^{17}$. The main advantage of using BMSCs for transplantation is their innate plasticity ${ }^{18)}$. In vitro bone differentiation of BMSCs prior to transplantation may enhance engraftment efficiency. The present study evaluated the reconstruction effects of BMSCs and osteoblast-like cells differentiated from BMSCs in VEGF-SF-CS scaffolds and SF-CS scaffolds, and analyzed the effects of VEGF in SF-CS scaffold and in vitro biocompatibility for the first time.

Cell delivery vehicles using biomaterials have been under development over the past decades. The most common approach has been to seed cells onto porous scaffolds ${ }^{19)}$. To guide the organization, growth, and differentiation of cells in tissue engineered constructs, the biomaterial scaffold should be able to provide not only a physical support for the cells but also the chemical and biological cues needed in forming functional tissues $^{20)}$. With the advancements in the field of bone tissue engineering, it has now become possible to BMSCs to multiple mesenchymal tissue lineages such as: osteogenic, chondrogenic and adipogenic tissues with the proper stimulation ${ }^{21}$. 
Scaffold materials are often critical for successful bone tissue regeneration using bone tissue engineering techniques. During the last few years, SF-CS scaffold has been recognized as a revolutionary material for applications in orthopedics and maxillofacial surgery due to it being biodegradable, biocompatible, and having osteoconductive properties ${ }^{22-24}$. They provide a porous interconnected environment for cells seeding and by-product circulation $^{25}$. In addition, they have been demonstrated to be noncytotoxic in vitro and to exhibit a good in vivo biocompatibility without inducing a strong leukocytic inflammatory host tissue response after implantation ${ }^{26}$. In our previous study, we mixed $\mathrm{SF}$ and CS into a 3D scaffold provide unique chemical, structural, and mechanical properties, which could be utilized for bone tissue engineering and regeneration applications. We previously found that the the most appropriate proportion between chitosan and silk fibroin is 5:5 for bone tissue engineering.

In addition to scaffold design, delivery of drugs or bone healing promoting factors is commonly employed in bone tissue engineering strategies to accomplish several functions required for bone tissue regeneration ${ }^{27-32}$. A group of growth factors known as VEGF has been studied extensively for applications related to bone regeneration. VEGF is a major regulator of angiogenesis. It is importance in triggering desired immune response and thus supports the bone healing process ${ }^{33}$. VEGF may couple angiogenesis to osteogenesis both indirectly through its effects on endothelial cells and directly by modulating chondrocytes, osteoblasts and osteoclasts that all express VEGF receptors ${ }^{34)}$. Earlier findings established that VEGF functions as a key inducer of bone vascularization but also indicated that the various cell types involved in bone metabolism, such as perichondrial progenitor cells, osteoblasts and osteoclasts can respond to VEGF signalling ${ }^{35}$. A direct effect of VEGF on osteogenic cells was suggested earlier by the increased proliferation, migration, differentiation and survival observed in human mesenchymal stem cells in vitro ${ }^{36}$.

Bone tissue engineering aims to address problems caused by bone trauma and disease. This newly emerging therapy usually involved the culture of a single cell type (such as the osteoblast) on a scaffold prior to patient implantation ${ }^{37}$. Until now, the effects of VEGF in SF-CS scaffold and in vitro biocompatibility have not been analyzed. In order to offer an ideal scaffold for bone tissue engineering, we added VEGF into SF-CS scaffold to reconstruct a $3 \mathrm{D}$ scaffold instead for the first time. This composite scaffold was hypothesized to be a useful carrier for BMSCs and growth factors that are relevant to bone regeneration. Finally, the in vitro approaches to the attachment, proliferation, and differentiation of ribbit BMSCs using VEGF-SF-CS scaffolds are described. The aim of the present study was to analyze the biocompatibility of the VEGF-SF-CS three-dimensional scaffolds in order to offer an ideal scaffold for bone tissue engineering.

\section{Materials and Methods}

\section{Materials}

Three healthy New Zealand white rabbits of either gender, aged 3 months, weighting about $3.0 \mathrm{~kg}$, were obtained from the Center for Experimental Animals at China Medical University (Shenyang, China) with a National Animal Use License number of SCXK-LN2011-0009. Animal use has been approved by Animal Use and Care Committee at China Medical University with a protocol number of CMU62043006. All experiments and surgical procedures were approved by the Animal Care and Use Committee at China Medical University, which complies with the National Institutes of Health Guide for the Care and Use of Laboratory Animals. All efforts were made to minimize the number of animals used and their suffering. Silk fibroin and Chitosan were chosen as they are widely used natural biomaterials in bone tissue engineering. Raw silk was purchased from nancong (Sichuan, China). Chitosan was purchased from tongxing company (Jiangsu, China). VEGF (121a.a.Human, $0.7 \mathrm{mg} /$ bottle) was purchased from PROSPEC company (Israel). CCK-8 $(0.5 \mathrm{mg} / \mathrm{ml})$ and ALP measurement kit(96T)was purchased from Jiancheng Biotechnology Institute(Nanjing, China). $\mathrm{NaHCO}_{3}, \mathrm{CaCl}_{2}$ and ethanol were bought from Nanjing (China). All other chemicals and reagents were of analytical grade unless specifically mentioned.

\section{BMSC isolation, culture and differentiation}

For the surgical procedures, the rabbits were anesthetized with $10 \%$ chloral hydrate $(0.35 \mathrm{ml} / 100 \mathrm{~g})$ intraperitoneally. Bone marrow (3-5 $\mathrm{ml}$ ) was extracted from rabbit femurs using a heparinized syringe, then centrifuged and washed with PBS. The cell suspension was centrifuged with Percoll lymphocyte separation medium, and the ivory white layer in the middle was collected, PBS washed and cultured in complete low-glucose DMEM. Cells were seeded in culture flasks at $1.0 \times 10^{4} \mathrm{cells} / \mathrm{cm}^{2}$ and incubated at $37^{\circ} \mathrm{C}$ in a humidified atmosphere with $5 \% \mathrm{CO}_{2}$. Half of the culture medium was exchanged after $24 \mathrm{~h}$, and completely exchanged after $48 \mathrm{~h}$, followed by medium changes every 2-3 days.Unattached cells were discarded by refreshing the medium. Cells at $85 \%$ confluency after 10-12 days, then trypsinized, centrifuged and passaged at a 1:2 ratio after 10-12 days. Third passage cells were induced to differentiate with osteogenesis induced liquid $(0.1 \mu \mathrm{Mol} / 1$ dexamethasone, $50 \mu \mathrm{mol} / \mathrm{ml}$ vitamin $\mathrm{C}, 10 \mathrm{mmol} / \mathrm{L} \beta$-glycerophosphate and containing 10\% fetal bovine serum glucose DMEM), followed by medium changes every $2-3$ days.

\section{Alkaline phosphatase staining}

BMSCs were evaluated for alkaline phosphatase activity 14 days after osteogenesis induction and in those without osteogenesis induction(control group). Cells were fixed for $10 \mathrm{~min}$ at $4{ }^{\circ} \mathrm{C}$ and 


\section{Shuang Tong et al:: In vitro Culture of BMSCs on VEGF-SF-CS Scaffolds}

incubated with a $2 \%$ cobalt nitrate and $1 \%$ ammonium sulfide (ALP kit, Hongqiao, Shanghai, $\mathrm{China}^{38}$ ). Areas stained tan were designated as positive.

\section{Von Kossa assay}

BMSCs plated in 6-well plates were fixed in $70 \%$ ethanol 18 days after osteogenesis induction in those without osteogenesis induction(control group). Cells were stained with von Kossa silver and placed under ultraviolet light for $10 \mathrm{~min}$. Cells were then treated with $5 \% \mathrm{NaS}_{2} \mathrm{O}_{3}$ for $2 \mathrm{~min}$, and washed with distilled water ${ }^{39)}$. Calcium nodules with a diameter greater than $1 \mathrm{~mm}$ were visualized by light-inverted microscope.

\section{Preparation of VEGF-SF-CS and SF-CS scaffold}

Bombyx mori silk fibers were treated twice with $0.5 \%(\mathrm{w} / \mathrm{w})$ $\mathrm{NaHCO}_{3}$ solution at $100{ }^{\circ} \mathrm{C}$ for $30 \mathrm{~min}$ and then rinsed with 70 ${ }^{\circ} \mathrm{C}$ distilled water to remove sericin for $30 \mathrm{~min}$. Then constant temperature drying with $50^{\circ} \mathrm{C}$ in the incubators overnight. Degummed silk was dissolved in a mix solvent system of $\mathrm{CaCl}_{2}(44.4 \mathrm{~g}) / \mathrm{CH}_{3} \mathrm{CH}_{2} \mathrm{OH}(46 \mathrm{ml}) / \mathrm{H}_{2} \mathrm{O}(57.5 \mathrm{ml})$ (mole ratio, 1:2:8) at $70{ }^{\circ} \mathrm{C}$ for $6 \mathrm{~h}$ and filtered to get a SF solution. After dialysis in a cellulose dialysis tubing $(\mathrm{MWCO}=50000)$ against distilled water for 3 days with water change every $12 \mathrm{~h}$ ). The final concentration of SF used was $8 \%$.

CS solutions were prepared by dissolving high molecularweight CS (82.7\% deacetylation; Tongxing China) at $3.66 \%$ (w/ v) in $2 \%$ acetic acid. The final concentration of CS used was $2 \%$.

VEGF solution was prepared by dissolving $0.7 \mathrm{mg}$ VEGF in $7 \mathrm{ml}$ deionised sterile water $(0.1 \mathrm{mg} / \mathrm{ml})$.

$\mathrm{SF} / \mathrm{CS}$ blend solutions $(100 \mathrm{ml})$ with $\mathrm{SF} / \mathrm{CS}$ weight ratio 5:5 was prepared in the same solvent system at $10 \mathrm{wt} \%$ (combined weight of CS and SF). After dialysis in a cellulose dialysis tubing $(\mathrm{MWCO}=50,000)$ against distilled water for 3 days with water change every $12 \mathrm{~h}, \mathrm{CS}$ and SF solutions were obtained. Then added/ $7 \mathrm{ml}$ VEGF solution, stirred in a magnetic stirrer for 50 minutes. Poured the CS, SF and VEGF solution into the 24 hole teflon culture plate. The CS, SF and VEGF solution was lyophilized (VFD-2000, Boyikang, PRChina) to obtain VEGF-SF-CS scaffold. Then we prepared SF-CS scaffolds by the same method.

To improve water stability, the dry VEGF-SF-CS and SF-CS scaffold were treated in methanol solution (concentration $<10 \%$ ) for $2 \mathrm{~h}$ to crystallize the SF content and neutralize the CS content. The VEGF-SF-CS and SF-CS scaffold was lyophilized to remove the excess methanol.

\section{BMSCs seeding}

The scaffolds were sterilized with $75 \%$ alcohol under ultraviolet light overnight and then rinsed extensively three times with sterile PBS. Before cell culturing, scaffolds were pre-wetted by immersion in DMEM for $12 \mathrm{~h}$ in the $37{ }^{\circ} \mathrm{C}$ incubator.
The BMSCs were cultured onto VEGF-SF-CS scaffolds, SFCS scaffolds and 24-well tissue culture plate wells (control group; $\mathrm{n}=3$; diameter $15 \mathrm{~mm}$; hight $13 \mathrm{~mm}$ ) for 3 and 6 days after osteogenesis induction at $37{ }^{\circ} \mathrm{C}$ under an atmosphere of $5 \% \mathrm{CO}_{2}$ and $95 \%$ air, with the original cell culture density of 4,000 cells/ well.

\section{BMSCs Morphology on scaffolds}

The morphology of BMSCs after osteogenesis induction on the VEGF-SF-CS scaffold and SF-CS scaffold was observed on day 1, 3 and 7 by SEM. The samples were washed with PBS and fixed with $3.0 \%$ glutaraldehyde at $4{ }^{\circ} \mathrm{C}$ for $4 \mathrm{~h}$. Subsequently, they were dehydrated through a series of graded ethanol (30,50, 70, 80, 90, 95 and $100 \%$ ), air-dried overnight, and sputtered with gold for SEM observation. Adherent cell morphology, patterns of cellular adherence with respect to structural features of the VEGFSF-CS scaffold and SF-CS scaffold, cell-cell interactions, and adherent cell density were assessed.

\section{The adhesion of BMSCs on scaffolds}

BMSCs after osteogenesis induction on the VEGF-SF-CS scaffold, SF-CS scaffold and control group were harvested and the concentration adjusted to $1 \times 10^{4} / \mathrm{ml}$. Cells were placed in cell culture plates precoated with VEGF-SF-CS scaffold and SF-CS scaffold, $1 \mathrm{ml}$ per well. Cells cultured in culture plates with no scaffold served as controls. 6 parallel wells were used for each group. Cells were cultured in an incubator at $37^{\circ} \mathrm{C}$ with $5 \% \mathrm{CO}_{2}$. The number of non-adhered cells was quantified at1, 2, 4, 8 and $24 \mathrm{~h}$.

The cell adhesion rate $(\%)=($ number of seeded cells - nonadhered cells)/number of seeded cells $\times 100 \%$.

\section{CCK-8 Test of BMSCs on scaffolds}

In order to examine whether grafted cells were survived, cell viability and proliferation was determined by using CCK-8. Briefly, after samples were cultured 1,3,5 and 7 days, the culture medium was replaced with serum free culture medium containing CCK-8 $(0.5 \mathrm{mg} / \mathrm{ml})$. Cultured for $4 \mathrm{~h}$, the samples were transferred to a $96-$ well plate. The absorbance was measured at $450 \mathrm{~nm}$ using an ELISA reader (Bio-Rad Model 550,USA).

\section{Alkaline Phosphatase (ALP) Activity of BMSCs on scaffolds}

The intracellular ALP activity in the scaffolds and control group was measured using an ALP measurement kit. Briefly, after samples were cultured 1, 4, 7 and 10 days, then washed with PBS for 3 times. Samples and control group with BMSCs were immersed in 500 microlitre cell lysis solution containing $0.1 \%$ Triton $\mathrm{X}-100$ and $5 \mathrm{mM} \mathrm{MgCl}$ through overnight. The whole solution was transferred to a tube and centrifuged at $13,000 \mathrm{rpm}$ for $10 \mathrm{~min}$ at $4{ }^{\circ} \mathrm{C}$. ALP activity was measured by mixing $50 \mu \mathrm{l}$ of 
J.Hard Tissue Biology Vol. 24(2):123 -133, 2015

Table 1 CCK-8 Assay of BMSCs on Different Scaffolds and Control Group ( $\mathrm{x} \pm \mathrm{s}, \mathrm{n}=3$ )

\begin{tabular}{llllll}
\hline Time & VEGF-SF-CS & \multicolumn{1}{c}{ SF-CS } & Control Group & $\mathrm{F}^{\mathrm{a}}$ & $\mathrm{P}^{\mathrm{a}}$ \\
\hline $1 \mathrm{~d}$ & $0.476 \pm 0.016$ & $0.469 \pm 0.014$ & $0.484 \pm 0.023$ & 0.535 & 0.611 \\
$3 \mathrm{~d}$ & $0.967 \pm 0.133$ & $0.921 \pm 0.051$ & $0.881 \pm 0.030$ & 15.038 & 0.005 \\
$5 \mathrm{~d}$ & $1.324 \pm 0.330$ & $1.215 \pm 0.424$ & $1.164 \pm 0.037$ & 13.991 & 0.006 \\
$7 \mathrm{~d}$ & $1.521 \pm 0.599$ & $1.390 \pm 0.737$ & $1.264 \pm 0.456$ & 13.393 & 0.006 \\
$\mathrm{~F}^{\mathrm{b}}$ & 82.746 & 99.080 & 174.859 & & \\
$\mathrm{P}^{\mathrm{b}}$ & 0.001 & 0.000 & 0.000 & & \\
\hline
\end{tabular}

${ }^{a}$ The comparison of different groups at the same time; ${ }^{b}$ The comparison of same groups at the different time.

Table 2. ALP Assay of BMSCs on Different Scaffolds and Control Group (U/g prot, 4000 cells/wel, $n=4$ )

\begin{tabular}{rlllll}
\hline Time & VEGF-SF-CS & SF-CS & Control Group & $\mathrm{F}^{\mathrm{a}}$ & $\mathrm{P}^{\mathrm{a}}$ \\
\hline $1 \mathrm{~d}$ & $2.465 \pm 0.049$ & $2.449 \pm 0.035$ & $2.441 \pm 0.026$ & 0.385 & 0.691 \\
$4 \mathrm{~d}$ & $5.317 \pm 0.242$ & $4.303 \pm 0.162$ & $3.874 \pm 0.145$ & 63.254 & 0.001 \\
$7 \mathrm{~d}$ & $9.833 \pm 0.516$ & $7.871 \pm 0.434$ & $6.036 \pm 0.387$ & 71.712 & 0.000 \\
$10 \mathrm{~d}$ & $12.766 \pm 0.514$ & $9.594 \pm 0.533$ & $7.452 \pm 0.495$ & 108.157 & 0.000 \\
$\mathrm{~F}^{\mathrm{b}}$ & 573.059 & 339.679 & 191.119 & & \\
$\mathrm{P}^{\mathrm{b}}$ & 0.001 & 0.000 & 0.000 & & \\
\hline
\end{tabular}

${ }^{a}$ The comparison of different groups at the same time; ${ }^{b}$ The comparisonof same groups at the different time.

supernatant with 50 microlitre p-nitrophenyl phosphate $(5 \mathrm{mM})$ in $150 \mathrm{mM}$ 2-amino-2-methyl-1-propanol buffer solution at room temperature for $30 \mathrm{~min}$ in dark. Following the incubation period, the reaction was stopped by adding $50 \mu$ of $0.2 \mathrm{~N} \mathrm{NaOH}$ to denature ALP and the OD was measured at $520 \mathrm{~nm}$ using an ELISA reader(Bio-Rad Model 550,USA).

\section{Statistical analysis}

All quantitative data were expressed as the means $\pm \mathrm{SD}$. Statistical analyses were performed using the statistic program SPSS 17.0. Results were analyzed by one-way ANOVA with a Student's t-test. Probability values of less than 0.05 were considered statistically significant. Before results analyzed by oneway ANOVA, all quantitative data obeyed the normality distribution.

\section{Results}

\section{Cell morphology}

Cell morphology was studied using a light-inverted microscope(Figure 1), BMSCs demonstrated good survival, and rapid proliferation.

In primary cells, BMSCs were a round morphology (Fig.1a). After 12 hour, BMSCs were attached to the culture flasks sparsely and displayed a fibroblast-like, spindle-shaped morphology (Fig.1b). After 3-4 days of incubation, cell number increased and cells continued to grow, proliferation started and the cells gradually grew into small colonies, displayed an elongated spindle shape, cells grew well and actively proliferated, they assumed a more spindle-shaped, fibroblastic morphology (Fig.1c). This pattern continued and was more evident after 5 days, The hematopoietic cells exhibited a typical cobblestone morphology at high magnification (Fig.1d). After 10-12 days majority of the cells were attached and acquired large, flattened or multilayer growth morphology (Fig.1e) and did not change throughout different passages (Fig.1f).

\section{Osteogenic differentiation of BMSCs}

Two weeks latter, alkaline phosphatase staining was greater in BMSCs after osteogenesis induction (Fig.2a) than in those without osteogenesis induction (Fig.2b). In addition, von Kossa staining 2 weeks after osteogenesis induction (Fig.2c) revealed a significant increase in calcium nodules when compared to those without osteogenesis induction groups (Fig.2d).

\section{Adhesion rate of BMSCs}

After $1 \mathrm{~h}, 3 \mathrm{~h}$ and $6 \mathrm{~h}$, cell adhesion rate was increased with time up in three groups. The adhesion rate in VEGF-SF-CS group and SF-CS group were higher than that in control group $(\mathrm{P}<0.01)$. In $1 \mathrm{~h}$, the major populations of adhesion rate in SF-CS scaffolds were nearly the same as those in VEGF-SF-CS scaffolds, there were no significant differences between scaffolds groups $(\mathrm{P}>0.05)$. After $3 \mathrm{~h}$ and $6 \mathrm{~h}$, there was a significant increase in adherent cells as compared to $1 \mathrm{~h}$. The adhesion rate in VEGF-SF-CS group and SF-CS group was significantly higher than that in control group $(\mathrm{P}<0.01)$, but there were still no significant differences between scaffolds groups $(\mathrm{P}>0.05)$. We proved that the SF-CS 
Shuang Tong et al.: In vitro Culture of BMSCs on VEGF-SF-CS Scaffolds
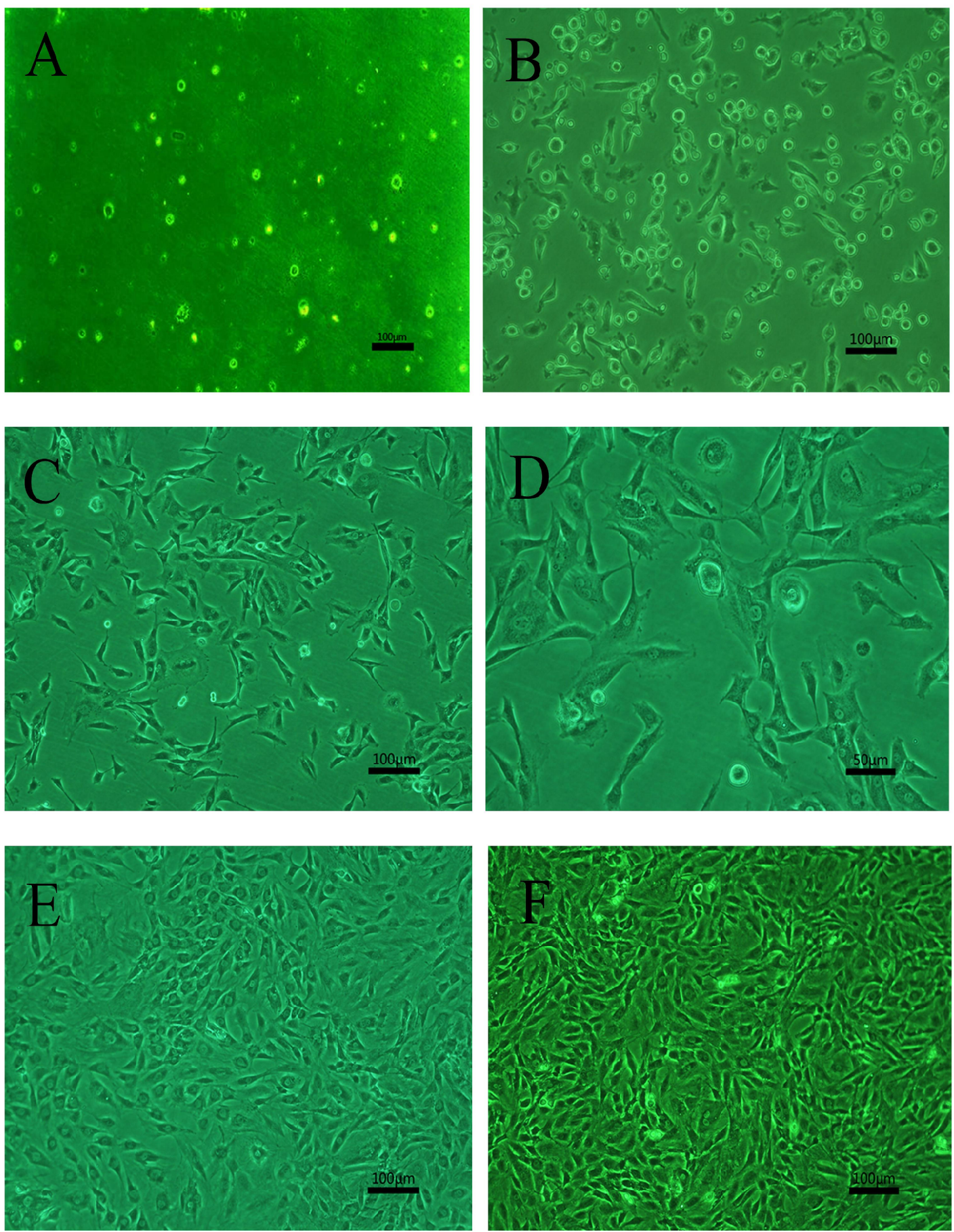

Figure 1. Cell morphology of BMSCs by a light-inverted microscope. a: Primary cells; b: Cultured 12 h; c: Cultured 3 day; d: Hematopoietic cells exhibited a typical cobblestone morphology at high magnification; e: Cultured 12 day; f: Third passage BMSCs.

scaffolds could increase adhesion of BMSCs. It also proved that the VEGF unable to promote BMSCs adhesion in the SF-CS scaffolds.

\section{SEM images of the BMSCs cultured with the VEGF-SF-CS scaffolds}

Growth of osteogenically induced BMSCs on scaffold cellular attachment and interaction within the VEGF-SF-CS scaffold and SF-CS scaffolds were evaluated by electron microscopy.

Growth of cells on scaffold at 1 day, scattered round cells adhered to the scaffold and a large number of particles were observed on the cell surface. Cell microfilaments were connected 

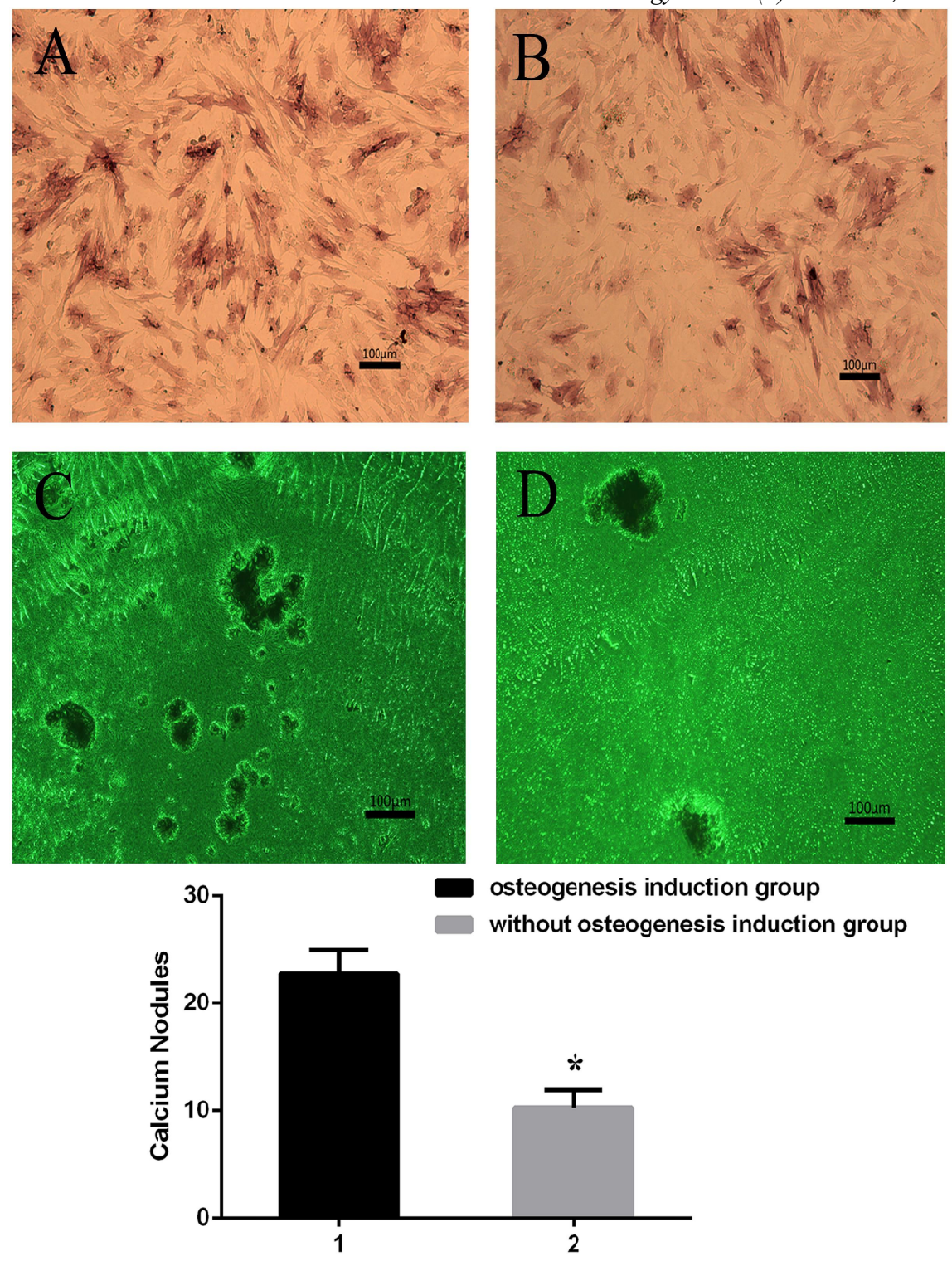

with the scaffold material (Fig 4a).

For 3 days cultured in osteogenic media, a large number of cells had adhered to the surface and pores of the scaffold. The cell aggregates became enlarged and actively proliferated. SEM results showed that single round cells became polygonal or triangular. Granular and filiform substances were observed around the cells. Cell microfilaments and pseudopodia were tightly connected to the scaffold (Fig 4b).

At 7 days, an increased number of cells had adhered to the surface and pores of the scaffold compared with 3 days, and cells grew and proliferated well. They exhibited typical osteoblast cell morphology and adhered tightly on the scaffolds surface or inside by formation of lamellipodia and filopodia, regarded as cells spreading, there were a number of cells present that are extending towards other cells in the culture. Cells were attached well on VEGF-SF-CS scaffolds and appeared spreaded and most cells were collected together to form cellular aggregations, which is crucial
Figure 2 In vitro analysis of osteogenic differentiation after BMSCs osteogenesis induction and in those without osteogenesis induction.

(a) Alkaline phosphatase expression 14 days after BMSCs osteogenesis induction.

(b) Alkaline phosphatase expression 14 days after BMSCs without osteogenesis induction.

(c) and (d) Von Kossa assay comparing calcium nodules between BMSCs osteogenesis induction(c) and BMSCs without osteogenesis induction (d) after 18 days culture. (e) Quantitative analysis of calcium nodules present in the two groups. A significant increase is seen in the BMSCs osteogenesis induction group when compared with BMSCs without osteogenesis inductionl groups, ${ }^{*} \mathrm{p}<0.05$. for the viability and function of BMSCs in vitro. The SF-CS scaffolds showed sparse or less attachment of cells as compared to VEGF-SF-CS scaffolds (Fig. 4c).

\section{CCK-8 test}

The proliferation of BMSCs on VEGF-SF-CS scaffolds, SFCS scaffolds and control group cultured for 1, 3, 5 and 7 days were compared by CCK-8 assay. The absorbance value for both the VEGF-SF-CS scaffolds and SF-CS scaffolds gradually increased, indicating significant cell growth within both scaffolds. The data are shown in Ttable 1. Data of BMSCs cultured without scaffolds was also present. The cell number increased with culture time. The BMSCs proliferated well in both VEGF-SF-CS scaffolds and SF-CS scaffolds, there were no significant differences with the cells cultured in control group at the 1 day $(\mathrm{p}>0.05)$. But after 3 day, data of BMSCs cultured in the VEGF-SF-CS scaffolds high above the cells cultured in the SF-CS scaffolds, and data of BMSCs 
Shuang Tong et al.: In vitro Culture of BMSCs on VEGF-SF-CS Scaffolds

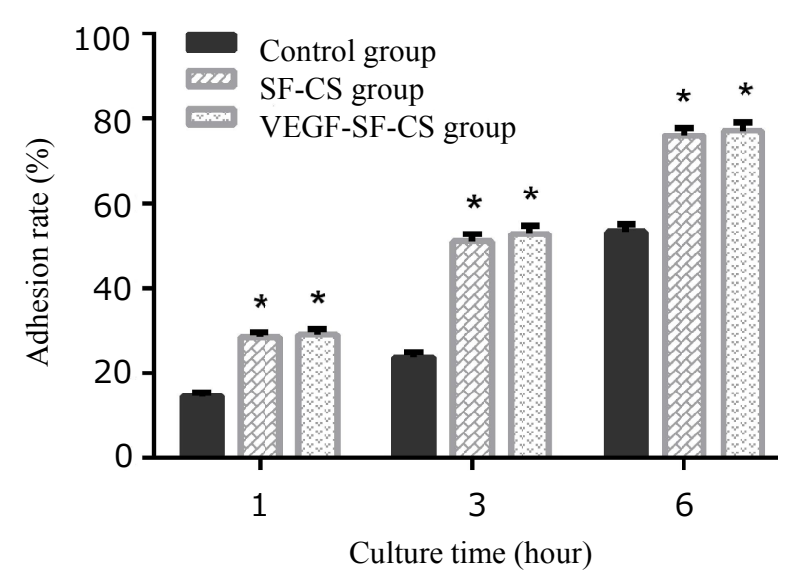

Figure 3. Adhesion rate of BMSCs , ${ }^{*}$ denote $\mathrm{P}<0.05$ compared with control group

cultured in both of scaffolds remarkably higher than those cultured without scaffolds, statistically significant differences $(p<0.05)$.

\section{Alkaline phosphatase (ALP) activity}

To evaluate the osteoblastic differentiation of the mesenchymal stem cells in the VEGF-SF-CS scaffolds, SF-CS scaffolds, we measured the alkaline phosphatase (ALPase) activity using spectrophotometry. The ALP activity of BMSCs cultured in the VEGF-SF-CS scaffolds, SF-CS scaffolds and control group was shown in Table 2. Fortotal ALP activity measurement, during culture period from day 1 , there was no significant difference in OD values between VEGF-SF-CS, SF-CS and control group $(\mathrm{P}>0.05)$, but from day 4 to 10 , a significant difference in OD values was found between scaffolds groups and the control group $(\mathrm{p}<0.01)$. The OD values in VEGF-SF-CS groups was the highest. This suggests the effect of VEGF on the activity of BMSCs. As culture time from day 4 to 10 , the growth trend of the OD values in three groups was increased rapidly. The OD values reached the peak at 10d. It means that the VEGF-SF-CS scaffolds are stable for prolonged culture system and the stabilized VEGF greatly enhance the ALPase activity.

\section{Discussion}

Osteoprogenitor cells, osteoconductive scaffolds and osteoinductive factors are the three main elements for forming tissue engineered bone. Highly porous scaffolds which performed the role of a temporary matrix for anchorage dependent cells are an important factor in the success of tissue engineering ${ }^{40-42}$. Composite scaffold was hypothesized to be a useful carrier for seed cells and growth factors that are relevant to bone regeneration. To maximize the capacity of BMSCs to regenerate bone, VEGF are generally used to promote differentiation into osteoblasts. VEGF have been reported to be effective in enhancing bone formation in a variety of animal studies. Various strategies for
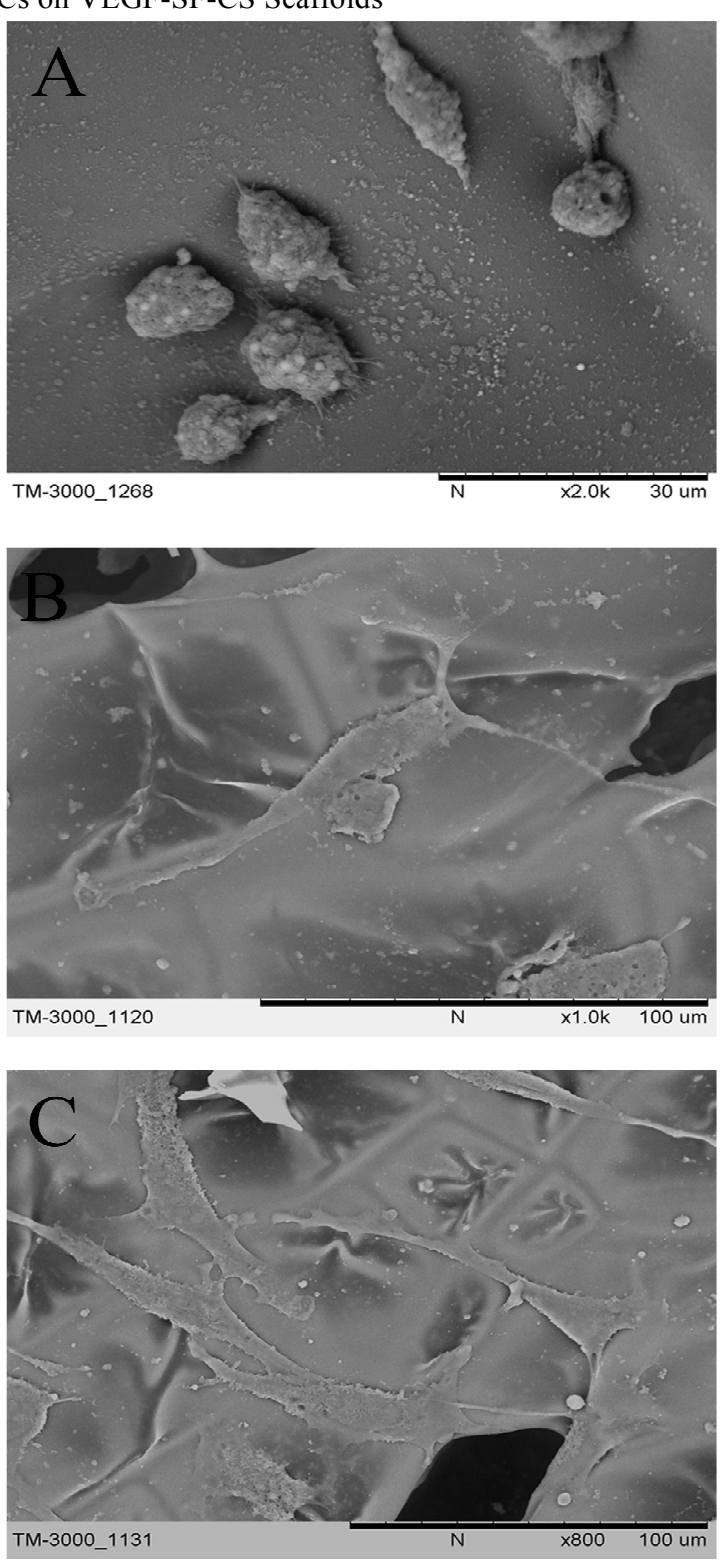

Figure 4. SEM images of BMSCs cultured with the VEGF-SF-CS scaffolds a: $1^{\text {st }}$ day; $b: 3^{\text {rd }}$ day; $c: 7^{\text {th }}$ day

manipulating BMSCs in order to overcome the low cellular survival and transdifferentiation potency of BMSCs after implantation are pretreatment with growth factors or preconditioning such as VEGF or osteogenesis induction to over express antideath signals ${ }^{43)}$.

SF facilitates cell adhesion and growth, and has relatively low thrombogenicity, low inflammatory response, and low protease susceptibility when highly crystallized ${ }^{4-47)}$. Chitosan is particularly attractive candidates in the scaffold composites due to their minimal inflammatory reactions or toxic degradation and good biodegradability coupled to excellent osteoconductivity in the case of bone graft ${ }^{48-50}$. A direct effect of VEGF on osteogenic cells was the increased proliferation, migration, differentiation ${ }^{51)}$. 
In the present study, a composite scaffold design was hypothesized to increase osteogenesis of BMSCs through incorporation of VEGF. We analyzed the VEGF-SF-CS composite scaffolds for bone tissue engineering applications. Such a scaffold may be particularly suited for implantation into bone defects due to its increased proliferation, migration, differentiation and osteoconductive. For this purpose, we added VEGF into SF-CS scaffold to reconstruct a 3D scaffold instead for the first time.

The BMSCs can be stimulated by Vitamin C, betaglycerophosphate, and dexamethasone that be added in culture media to differentiate to preosteoblasts before the BMSCs cultured onto VEGF-SF-CS scaffolds, because that can avoid BMSCs being induced into vascular endothelial cells by VEGF after seeded. To establish safety of BMSCs-engineered bone scaffolds, it is critical to evaluate their phenotypic stability ${ }^{52-53)}$.

Nominal differences in cellular adhesion and proliferation were observed between BMSCs after osteogenesis induction. Additionally these results suggested that the biomaterial was suitable for the proposed in vitro studies as it facilitated BMSCs initial attachment onto the surface, spreading and subsequent growth.

The time course of BMSCs-SF-CS adhesion clearly demonstrated adhesion of BMSCs to SF-CS scaffolds within minutes. The rapid time course of BMSCs adhesion to SF-CS scaffolds was significant, characterized by $29 \%$ adhesion by 60 min post-seeding. The adhesion rate of BMSCs in VEGF-SF-CS group and in SF-CS group significantly exceeded those in control group $(\mathrm{P}<0.05)$. Previous studies have indicated that SF-CS scaffolds increased adhesion and growth of BMSCs. These observations achieved our primary objective, namely, to determine if SF-CS scaffolds had the potential to establish an adhesive interface with BMSCs in vitro. It also proved that the VEGF unable to promote BMSCs adhesion in the SF-CS scaffolds.

7 days BMSCs morphology study by SEM was performed to further evaluate the biocompatibility of these scaffolds. The seeding of BMSCs on VEGF-SF-CS scaffolds up to 7 days resulted in completely polygonal or triangular cell morphology similar to what is typically observed in standard cell culture flasks. These observations confirmed the cell survival and proliferation on VEGF-SF-CS scaffolds, assuring its biocompatibility. The evidence of cell-to-cell interaction and cell spreading can be considered as signs of healthy cells and indicative for noncytotoxic response of the cells on VEGF-SF-CS scaffolds ${ }^{54-55)}$.

The level of cell growth and proliferation on the scaffolds and control group were assessed using CCK-8 and ALP assay in vitro. It could be seen that the absorbance index of the tested groups increased with the increase of culture time. In the first day, statistically no significant differences ( $p>0.05)$ were observed in the cell proliferation and differentiation among three groups. Data of BMSCs cultured in the VEGF-SF-CS scaffolds and SF-
CS scaffolds high above the cells cultured in the control group after 3-day culture, which implied that the scaffolds were beneficial to cell development. While the number of BMSCs on VEGF-SFCS scaffolds exhibited remarkably higher than those on SF-CS scaffolds. These results indicated that VEGF promoted the proliferation and differentiation of BMSCs significantly under our conditions. Our study is also suggestive evidence from in vitro experiments that VEGF may regulate bone formation through a direct effect on BMSCs. It has been reported that human VEGF binds to BMSCs in culture and is capable of inducing migration and alkaline phosphatase activity ${ }^{56}$. Our results indicate a difference in the proliferation and differentiation of BMSCs in the different types of scaffold. The reason for varied production of extracellular matrices in the different scaffolds may be due to the differences in chemical compositions of the matrices.

While fabricate the VEGF-SF-CS scaffold for bone tissue engineering, a critical part is to maintain bioactivity of VEGF in manufacturing VEGF-SF-CS scaffold, as during this manufacture course, VEGF bioactivity is mostly like to be destroyed in lyophilization and methanol crosslinking. In lyophilization course, usage of cryoprotector may reduce or even prevent influence of stress on activity of protein ${ }^{57)}$. Silk protein and chitsan can be used as cryoprotector to well maintain activity of VEGF ${ }^{58,59)}$. Alexander proved that conformation of protein treated with low concentration methanoll was basically not changed and covalent structure of protein molecule was not destroyed ${ }^{60)}$. We took the following measures in manufacture VEGF-SF-CS scaffold to prevent VEGF bioactivity from destroyed: 1. Set lyophilization temperature at $-40{ }^{\circ} \mathrm{C}$ and used silk and chitsan as cryoprotector to further maintain VEGF activity. 2. Methanol concentration $<10$ $\%$. 3. The whole VEGF-SF-CS manufacture processes were designed as a physical course. Through ALP and CCK-8 testing result, we could fundamentally believe that there was no obvious degradation of VEGF bioactivity.

In this experiment, SF-CS scaffold was manufactured in aqueous solution and might wrap active VEGF molecule without damaging VEGF activity. Mandal and Kundu utilized lyophilization to prepare 3D silk fibron scaffold wrapped with bovine serum albumin and then inspected on its in vitro release and performance ${ }^{61)}$. Kundu investigated VEGF loaded silk fibron protein continuously releasing within 3 weeks and proved that it could protect VEGF evenly and continuously releasing in silk fibron scaffold ${ }^{62)}$. Through ALP and CCK-8 test result, we could basically determine that in VEGF-SF-CS scaffold, VEGF could evenly and continuously release within certain period.

Interestingly, the enhancement of BMSCs proliferation and differentiation by VEGF is dependent on time. VEGF didn't promot the proliferation and differentiation of BMSCs significantly at early time (day 1 ), but had obvious effect when cultured at later time points (days 3-10), demonstrating that the 
Shuang Tong et al.: In vitro Culture of BMSCs on VEGF-SF-CS Scaffolds

effect of VEGF which promots the proliferation and differentiation of BMSCs is time dependent. These results indicate that correct VEGF delivery strategies greatly affect BMSCs proliferation and differentiation and should be considered when designing delivery system.

We compared, for the first time, the physiochemistry and osteogenesis of VEGF-SF-CS scaffolds and SF-CS scaffolds. Our results confirmed that VEGF-a bioactive growth factor-has a significant capacity to improve the in vitro bioactivity of SF-CS scaffolds. The results confirmed that the direct effect of VEGF on BMSCs was the increased proliferation, migration, differentiation and survival. The VEGF-SF-CS scaffolds are biocompatible and have no negative effects on the BMSCs in vitro. Our data supports the potential utility of SF-CS as a biocompatible scaffold. Our findings demonstrate that VEGF-SF-CS scaffolds are suitable substrates for bone tissue engineering and VEGF confers the potential physiological benefit of accelerated reconstruction. Future work will be conducted in a bone defect model of animals to investigate potential repaired reaction of the VEGF-SF-CS scaffolds, and to better understand the biomechanical properties and potential uses of VEGF-SF-CS scaffolds, as well as the boneforming capacity of this type of scaffold in animal models.

In conclusion, VEGF-SF-CS composite scaffolds represent a promising new type of scaffold for bone tissue engineering.

\section{Acknowledgements}

This work was supported by science and technology plan project of Liaoning province [grant number 2012-B00002012225082].

\section{References}

1. Vacanti JP and Langer R. Tissue engineering: The design and fabrication of living replacement devices for surgical reconstruction and transplantation. Lancet 354 (Suppl 11): SI32-SI34, 1999

2. Scheller EL, Krebsbach PH and Kohn DH. Tissue engineering: State of the art in oral rehabilitation. J Oral Rehabil 36:368389, 2009

3. Hankenson KD, Dishowitz M, Gray C and Schenker M. Angiogenesis in bone regeneration. Injury 42:556-561, 2011

4. Marsell R and Einhorn TA. The biology of fracture healing. Injury 42:551-555, 2011

5. Muschler GF, Nakamoto C and Griffith LG. Engineering principles of clinical cellbased tissue engineering. J Bone Joint Surg Am 86-A:1541-1558, 2004

6. Grayson WL, Chao PH, Marolt D, Kaplan DL and VunjakNovakovic G. Engineering custom-designed osteochondral tissue grafts. Trends Biotechnol 26:181-189, 2008

7. Vunjak-Novakovic G, Meinel L, Altman G and Kaplan D. Bioreactor cultivation of osteochondral grafts. Orthod
Craniofac Res 8: 209-218, 2005

8. Bruder SP, Kraus KH, Goldberg VM and Kadiyala S. The effect of implants loaded with autologous mesenchymal stem cells on the healing of canine segmental bone defects. J Bone Joint Surg Am 80: 985-996, 1998

9. Bruder SP, Kurth AA, Shea M, Hayes WC, Jaiswal N and Kadiyala S. Bone regeneration by implantation of purified, culture-expanded human mesenchymal stem cells. J Orthop Res 16: 155-162, 1998

10. Cui L, Liu B, Liu G, Zhang W, Cen L, Sun J, Yin S, Liu W and Cao Y. Repair of cranial bone defects with adipose derived stem cells and coral scaffold in a canine model. Biomaterials 28: 5477-5486, 2007

11. Kon E, Muraglia A, Corsi A, Bianco P, Marcacci M, Martin I, Boyde A, Ruspantini I, Chistolini P, Rocca M, Giardino R, Cancedda R and Quarto R. Autologous bone marrow stromal cells loaded onto porous hydroxyapatite ceramic accelerate bone repair in criticalsize defects of sheep long bones. J Biomed Mater Res 49: 328-337, 2000

12. Yamada Y, Ueda M, Naiki T, Takahashi M, Hata K and Nagasaka T. Autogenous injectable bone for regeneration with mesenchymal stem cells and plateletrich plasma: tissueengineered bone regeneration. Tissue Eng 10: 955-964, 2004

13. Meinel L, Fajardo R, Hofmann S, Langer R, Chen J, Snyder B, Li C, Zichner L, Langer R, Vunjak-Novakovic G and Kaplan DL. Silk implants for the healing of critical size bone defects. Bone 37: 688-698, 2005

14. Mankani MH, Kuznetsov SA, Wolfe RM, Marshall GW and Robey PG. In vivo bone formation by human bone marrow stromal cells: reconstruction of the mouse calvarium and mandible. Stem Cells 24: 2140-2149, 2006

15. Miura M, Miura Y, Sonoyama W, Yamaza T, Gronthos S and Shi S. Bone marrow-derived mesenchymal stem cells for regenerative medicine in craniofacial region. Oral Dis 12 : 514-522, 2006

16. Kassem M, Risteli L, Mosekilde L, Melsen F and Eriksen EF. Formation of osteoblast-like cells from human mononuclear bone marrow cultures. APMIS 99: 269-274, 1991

17. Pittenger MF, Mackay AM and Beck SC. Multilineage potential of adult mesenchymal stem cells. Science 284, 143147, 1999

18. Zipori D. The stem state: plasticity is essential, whereas self-renewal and hierarchy are optional. Stem Cells 23, 719726, 2005

19. Chen QZ, Harding SE, Ali NN, Lyon AR and Boccaccin AR. Biomaterials in cardiac tissue engineering: ten years of research survey. Mater Sci Engin Rep 59, 1-37, 2008

20. Langer R and Tirrell DA. Designing materials for biology and medicine. Nature 428, 487-492, 2004 
21. Pittenger MF, Mackay AM, Beck SC, Jaiswal RK, Douglas R, Mosca JD, Moorman MA, Simonetti DW, Craig S and Marshak DR. Multilineage potential of adult human mesenchymal stem cells. Science 284: 143-147, 1999

22. Park SJ, Lee KY, Ha WS and Park SY. Structural changes and their effect on mechanical properties of silk fibroin/ chitosan blends. J Appl Poly Sci 74: 2571-2575, 1999

23. El Sayed K, Marzahn U and John T. PGA-associated heterotopic chondrocyte cocultures: implications of nasoseptal and auricular chondrocytes in articular cartilage repair. J Tiss Engin Regen Med 7: 61-72, 2013

24. De Santis R, Gloria A and Russo T. A basic approach toward the development of nanocomposite magnetic scaffolds for advanced bone tissue engineering. J Appl Poly Sci 122: 3599-3605, 2011

25. Gogolewski S and Gorna K. Biodegradable polyurethane cancellous bone graft substitutes in the treatment of iliac crest defects. J Biomed Mater Res A 80: 94-101, 2007

26. Laschke MW, Strohe A, Scheuer C, Eglin D, Verrier S and Alini M. In vivo biocompatibility and vascularization of biodegradable porous polyurethane scaffolds for tissue engineering. Acta Biomater 5:1991-2001, 2009

27. Ito Y. Tissue engineering by immobilized growth factors. Mater Sci Eng C 6:267-274, 1998

28. Ahrendt G, Chickering DE and Ranieri JP. Angiogenic growth factors: a review for tissue engineering. Tissue Eng 4:117130, 1998

29. Boden S. Bioactive factors for bone tissue engineering. Clin Orthop Relat Res S 84-94, 1999

30. Babensee JE, McIntire LV and Mikos AG. Growth factor delivery for tissue engineering. Pharm Res 17: 497-504, 2000

31. Tabata Y. Tissue regeneration based on growth factor release. Tissue Eng 9:S5-S15, 2003

32. Rose FRAJ, Hou Q and Oreffo ROC. Delivery systems for bone growth factors-the new players in skeletal regeneration. J Pharm Pharmacol 56: 415-427, 2004

33. Akeson AL, Greenberg JM, Cameron JE, Thompson FY, Brooks SK, Wiginton D and Whitsett JA. Temporal and spatial regulation of VEGF-A controls vascular patterning in the embryonic lung. Dev Bio 264: 443-455, 2003

34. Dias S, Hattori K, Zhu Z, Heissig B, Choy M, Lane W, Wu Y, ChadburnA, Hyjek E, Gill M, Hicklin DJ, Witte L, Moore MA and Rafii S. Autocrine stimulation of VEGFR- 2 activates human leukemic cell growth and migration. J Clin Invest 106: 511-521, 2000

35. Dai J and Rabie AB. VEGF: an essential mediator of both angiogenesis and endochondral ossification. J Dent Res 86 : 937-950, 2007

36. Street J and Lenehan B. Vascular endothelial growth factor regulates osteoblast survival-evidence for an autocrine feedback mechanism. J Orthop Surg Res 4: 19, 2009

37. Lyons F, Partap S and O'Brien FJ. Part 1: scaffolds and surfaces. Technol Health Care 16: 305-317, 2009

38. Sun XJ, Zhang ZY, Wang SY, Gittens SA, Jiang XQ and Chou LL. Maxillary sinus floor elevation using a tissueengineered bone complex with osteobone and bMSCs in rabbits. Clin Oral Implants Res 19:804-813, 2008

39. Aghaloo T, Jiang X, Soo C, Zhang Z, Zhang X and Hu J. A study of the role of Nell-1 gene modified goat bone morrow stromal cells in promoting new bone formation. Mol Ther 15: 1872-1880, 2007

40. Wang Y, Kim HJ, Vunjak-Novakovic G and Kaplan DL. Stem cell-based tissue engineering with silk biomaterials. Biomaterials 27 (36): 6064-682, 2006

41. Li C, Vepari C, Jin HJ, Kim HJ and Kaplan DL. Electrospun silk-BMP-2 scaffolds for bone tissue engineering. Biomaterials 27 (16): 3115-324, 2006

42. Meinel L, Betz O, Fajardo R, Hofmann S, Nazarian A and Cory E. Silk based biomaterials to heal critical sized femur defects. Bone 39 (4): 922-931, 2006

43. Song H, Song BW, Cha MJ, Choi IG and Hwang KC. Modification of mesenchymal stem cells for cardiac regeneration. Exp Opin on Biolol Thera 10: 309-319, 2010

44. Altman GH, Diaz F, Jakuba C, Calabro T, Horan RL and Chen J. Silk-based biomaterials. Biomaterials 24: 401-416, 2003

45. Hardy JG and Scheibel TR. Composite materials based on silk proteins. Prog Polym Sci 35: 1093-1115, 2010

46. Mandal BB and Kundu SC. Cell proliferation and migration in silk fibroin 3D scaffolds. Biomaterials 30: 2956-2965, 2009

47. Bhardwaj $\mathrm{N}$ and Kundu SC. Electrospinning: a fascinating fiber fabrication technique. Biotech Adv 28: 325-347, 2010

48. Di Martino A, Sittinger M and Risbud MV. Chitosan: A versatile biopolymer for orthopaedic tissue-engineering. Biomaterials 26:5983-5990, 2005

49. Lee KY, Jeong L, Kang YO, Lee SJ and Park WH. Electrospinning of polysaccharides for regenerative medicine. Adv Drug Deliv Rev 61: 1020-1032, 2009

50. Shi C, Zhu Y, Ran X, Wang M, Su Y and Cheng T. Therapeutic potential of chitosan and its derivatives in regenerative medicine. J Surg Res 133: 185-192, 2006

51. Ferrara N and Davis-Smyth T. The biology of vascular endothelial growth factor. Endocr Rev 18: 4-25, 1997

52. Kuznetsov SA, Cherman N and Robey PG. In vivo bone formation by progeny of human embryonic stem cells. Stem Cells Dev 20:269-287, 2011

53. Bielby RC, Boccaccini AR, Polak JM and Buttery LD. In vitro differentiation and in vivo mineralization of osteogenic 
Shuang Tong et al.: In vitro Culture of BMSCs on VEGF-SF-CS Scaffolds

cells derived from human embryonic stem cells. Tissue Eng 10: 1518-1525, 2004

54. Nwe N, Furuike T and Tamura H. The mechanical and biological properties of chitosan scaffolds for tissue regeneration templates are significantly enhanced by chitosan from gongronella butleri. Materials 2: 374-398, 2009

55. Neamnark A, Sanchavanakit N, Pavasant P, Bunaprasert T, Supaphol P and Rujiravanit R. In vitro biocompatibility evaluations of hexanoyl chitosan film. Carbohydrate Polymers 68: 166-172, 2007

56. Midy V and Plouet J. Vasculotropin/vascular endothelial growth factor induces differentiation in cultured osteoblasts. Biochem Biophys Res Commun 199: 380-386, 1994

57. Alan $\mathrm{H}$ and Haines. Non-equivalence of $\mathrm{D}$-and L-trehalose in stabilising alkaline phosphatase against freeze-drying and thermal stress. Is chiral recognition involved? Organ Biomol Chem 4: 702-706, 2006
58. Kreilgaard L, Jones LS, Randolph TW, Frokjaer S, Flink JM, Manning MC and Carpenter JF. Effect of Tween 20 on freeze-thawing- and agitation-induced aggregation of recombinant human factor XIII. J Pharma Sci 87 (12): 15971603, 1998

59. Pikal-Cleland KA and Carpenter JF. Lyophilization-induced protein denaturation in phosphate buffer systems: monomeric and tetrameric beta-galactosidase. J Pharma Scie 90 (9): 1255-1268, 2001

60. Alexander M. Klibanov Enzymatic catalysis in anhydrous organic solvents. Trends Biochem Sci 14 (4): 141-144, 1989

61. Mandal BB and Kundu SC. Calcium alginate beads embedded in silk fibroin as 3D dual drug releasing scaffolds. Biomaterials 30 (28): 5170-5177, 2009

62. Kundu J, Chung YI, Kim YH, Tae G and Kundu SC. Silk fibroin nanoparticles for cellular uptake and control release. Int J Pharma 388 (1-2): 242-250, 2010 